\title{
A synthetic defective interfering SARS-CoV-2
}

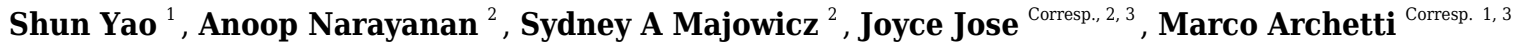 \\ 1 Department of Biology, Pennsylvania State University, University Park, United States \\ 2 Department of Biochemistry \& Molecular Biology, Pennsylvania State University, University Park, United States \\ 3 The Huck Institutes for the Life Sciences, Pennsylvania State University, University Park, United States \\ Corresponding Authors: Joyce Jose, Marco Archetti \\ Email address: jxj321@psu.edu, mua972@psu.edu
}

Viruses thrive by exploiting the cells they infect, but in order to replicate and infect other cells they must produce viral proteins. As a result, viruses are also susceptible to exploitation by defective versions of themselves that do not produce such proteins. A defective viral genome with deletions in protein-coding genes could still replicate in cells coinfected with full-length viruses. Such defective interfering genome could even replicate faster due to its shorter size, interfering with the replication of the virus. We have created a synthetic defective interfering version of SARS-CoV-2, the virus causing the Covid-19 pandemic, assembling parts of the viral genome that do not code for any functional protein but enable the genome to be replicated and packaged. This synthetic defective genome replicates three times faster than SARS-CoV-2 in coinfected cells, and interferes with it, reducing the viral load of infected cells by half in 24 hours. The synthetic genome is transmitted as efficiently as the full-length genome, suggesting the location of the putative packaging signal of SARS-CoV-2. A version of such a synthetic construct could be used as a self-promoting antiviral therapy: by enabling replication of the synthetic genome, the virus would promote its own demise. 
1 A Synthetic Defective Interfering SARS-CoV-2

2

\begin{abstract}
Viruses thrive by exploiting the cells they infect, but in order to replicate and infect other cells they must produce viral proteins. As a result, viruses are also susceptible to exploitation by defective versions of themselves that do not produce such proteins. A defective viral genome with deletions in protein-coding genes could still replicate in cells coinfected with full-length viruses. Such defective interfering genome could even replicate faster due to its shorter size, interfering with the replication of the virus. We have created a synthetic defective interfering version of SARS-CoV-2, the virus causing the Covid-19 pandemic, assembling parts of the viral genome that do not code for any functional protein but enable the genome to be replicated and packaged. This synthetic defective genome replicates three times faster than SARS-CoV-2 in coinfected cells, and interferes with it, reducing the viral load of infected cells by half in 24 hours. The synthetic genome is transmitted as efficiently as the full-length genome, suggesting the location of the putative packaging signal of SARS-CoV-2. A version of such a synthetic construct could be used as a self-promoting antiviral therapy: by enabling replication of the synthetic genome, the virus would promote its own demise.
\end{abstract}

\title{
Introduction
}

Versions of a viral genome with large deletions arise frequently from most RNA viruses when passaged in vitro [Gard et al. 1952, Huang \& Baltimore 1970, Brian \& Spaan 1997, Vignuzzi \& López 2019]. Defective genomes lacking essential coding sequences can still replicate and be packaged into virions in the presence of functional full-length viruses. The full viral genome produces the essential proteins for replication and packaging, which can be exploited by defective genomes that retain the ability to bind to these proteins. These defective genomes can be considered parasites of the full-length virus, as they compete for replication and packaging and, given their shorter length, can replicate faster than (and interfere with) their parental fulllength viral genome in coinfected cells. 
47 Such defective interfering (DI) genomes have been described - and indeed appear to be common

48 - in coronaviruses [Kim et al. 1993a,b, Mendez et al. 1996, Brian \& Spaan 1997, Izeta et al.

49 1999, Graham et al. 2005, Fehr \& Perlman 2015, Vignuzzi \& López 2019], where they have

50 been used to locate the functional elements of their genomes. In SARS-CoV-2, the virus

51 responsible for the current Covid-19 pandemic [Wu et al. 2020, Zou et al. 2020], long deletions

52 have been reported [Kim et al. 2020], and DI genomes have been shown to arise by

53 recombination driven by sequence microhomology [Gribble et al. 2021].

54

55

56

57

58

59

60

61

62

63

64

65

66

67

68

69

70

71

72

73

74

75

We made short synthetic DI RNAs from parts of the SARS-CoV-2 genome to test whether these DI genomes could replicate in coinfected cells and be packaged into virions. If our DI genomes replicate faster than the wild type (WT) virus genome, the DIs could impair the intracellular growth of the virus, and if the DI genomes get packaged efficiently into virions, this interference could continue over time.

The design of our DI genomes was based on observations from natural defective interfering coronaviruses [TGEV: Mendez et al. 1996; MHV: Makino et al. 1985, 1988, 1990, Van der Most et al. 1991; Kim et al. 1993a, Kim et al. 1995, Masters 1994; Goebel et al. 2007; BCoV: Chang et al. 1994, Chang \& Brian 1996; Williams et al. 1999; Raman et al. 2005; Brown et al. 2007; 229E: Thiel et al. 1998; IBV: Penzes et al. 1994, Dalton et al. 2001; reviewed by Yang \& Leibowitz 2015] suggesting that the 3' and 5' untranslated regions (UTRs) are essential for replication and that the putative packaging signal resides inside the nsp15 sequence [TGEV: Escors et al. 2003, Morales et al. 2013; Hsieh et al. 2005; Hsin et al. 2018; MHV: Fosmire et al. 1992, Kuo \& Masters 2013, Woo et al. 2019; BCoV: Cologna \& Hogue 2000] - a conclusion that is however disputed for A betacoronaviruses, which lack the RNA structure responsible for packaging [Masters 2019]. DI genomes that occur naturally in SARS-CoV-2 often retain the 5'UTR and 3'UTR; $80 \%$ of these DIs have single deletions; the most abundant DI genomes with double deletions have a very short terminal deletion and a long central one [Gribble et al. 2021].

Our main synthetic construct is made from three portions [Figure 1]: the 5' UTR and the adjacent 5' part of nsp1 in ORF1a, a part of nsp15 that includes the putative packaging signal, and the sequence spanning the 3' part of the N sequence, ORF10 and the 3'UTR. We chose the N fragment to include two of the most conserved regions of the virus genome [Rangan et al. 2020] (28990-29054 and 28554-28569). Because there is evidence that a long ORF enables DIs in certain coronaviruses (notably MHV [De Groot et al. 1992], which is closely related to SARS$\mathrm{CoV}-2$ ) to replicate more efficiently (even if coding for a chimeric non-functional protein [Van der Most et al. 1995]), we assembled the three fragments in frame, to retain a 2247nt ORF starting at the 5' end of nsp1 [Figure 1]; and because there is evidence [Joo \& Makino 1995, VanMarle et al. 1995; Mendez et al. 1996] that multiple transcriptional regulatory sequences (TRS) reduce replication efficiency, we chose the 3' portion to start from within the N sequence, to exclude its TRS. Analysis of the predicted secondary structure of this synthetic RNA showed that the three portions fold essentially (except at the junctions) like the corresponding sequences in the full genome.

The length of our main synthetic DI genome $\left(\mathrm{DI}_{1}\right)$ is $2882 \mathrm{nt}, 9.6 \%$ of the full-length genome (29903 nt). We also synthesised a shorter $(800 \mathrm{nt})$ defective genome $\left(\mathrm{DI}_{0}\right)$ without the second portion (the putative packaging signal) and with shorter terminal portions [Figure 1] as control 
93

94

95

96

97

98

99

100

101

102

103

104

105

106

107

108

109

110

111

112

113

114

115

116

117

118

119

120

121

122

123

124

125

126

127

128

129

130

131

132

133

134

135

136

137

and to test the effects of the intersecting portions on replication and packaging. The $\mathrm{DI}_{1}$ and $\mathrm{DI}_{0}$ genomes, synthesised as DNA and cloned into plasmids, were transcribed in vitro to produce genomic RNAs, which were then electroporated in Vero-E6 cells, which were subsequently infected with SARS-CoV-2.

\section{Materials \& Methods}

Sequences and cloning. The DNA sequence of the $\mathrm{DI}_{1}$ genome (GenBank accession number: MW250351) was designed to correspond to the following three joint portions of the SARS-CoV2 complete genome (the NCBI Reference Sequence for SARS-CoV-2; GenBank accession number: NC_045512.2), in the following order: 1 to 789; 19674 to 20340; and 28478 to 29903. The $\mathrm{DI}_{0}$ genome (GenBank accession number: MW250350) was designed to correspond to the following two joint fragments of SARS-CoV-2 in the following order: 1 to 473; 29576 to 29903. In both cases, the first nucleotide of the first fragment was changed from A to $\mathrm{C}$ to improve in vitro transcription efficiency [Milligan 1987, Martin \& Coleman 1987]. The synthetic sequence was analysed using the Vienna RNA package [Lorenz et al. 2011] to confirm the absence of potential aberrations in the RNA secondary structure. The $\mathrm{DI}_{1}$ and $\mathrm{DI}_{0}$ genome $\mathrm{DNA}$ were assembled from synthetic oligonucleotides and inserted into a pMA-RQ plasmid by Invitrogen (Thermo Fisher Scientific). The minimal T7 promoter TAATACGACTCACTATAGG was synthesised immediately upstream of the 5 ' end of the synthetic virus sequence. A short sequence (CCATGG) containing the NcoI restriction site was synthesised immediately upstream of the 5' end of the T7 promoter, and a short sequence (CCGGT) containing the AgeI restriction site was synthesised immediately downstream of the 3 ' end of the third fragment. The plasmid DNA was purified from transformed bacteria and the final construct was verified by sequencing.

In vitro transcription. The plasmid containing the synthetic $\mathrm{DI}_{1}$ or $\mathrm{DI}_{0}$ genome $\mathrm{DNA}$ was linearized using NcoI and AgeI and resuspended in $\mathrm{H}_{2} \mathrm{O} .1 \mu \mathrm{g}$ was then used as a template to produce capped RNA via T7 RNA polymerase, using a single reaction setup of the mMESSAGE mMACHINE $\AA$ Kit (Applied Biosystems), which contains: $2 \mu \mathrm{L}$ enzyme mix (buffered 50\% glycerol containing RNA polymerase, RNase inhibitor, and other components); $2 \mu \mathrm{L}$ reaction buffer (salts, buffer, dithiothreitol, and other ingredients); $10 \mu \mathrm{L}$ of a neutralized buffered solution containing: $15 \mathrm{mM}$ ATP, $15 \mathrm{mM} \mathrm{CTP}, 15 \mathrm{mM} \mathrm{UTP,} 3 \mathrm{mM}$ GTP and 12mM cap analog [m7G(5')ppp(5')G]; $4 \mu \mathrm{L}$ nuclease-free $\mathrm{H}_{2} \mathrm{O}$; incubated for 2 hours at $37^{\circ} \mathrm{C}$. RNA was isolated using TRIzol reagent (Invitrogen) extraction and isopropanol precipitation.

Cells and transfection. Vero-E6 cells (ATCC: CRL-1586) cultured in DMEM medium (Hyclone, \#SH30022.FS) supplemented with 10\% fetal bovine serum (Corning, \#35-011-CV), 100 units $\mathrm{ml}^{-1}$ penicillin and $100 \mu \mathrm{g} \mathrm{ml}^{-1}$ streptomycin (Gibco, \#15140122) maintained at $37^{\circ} \mathrm{C}$ and in a $5 \% \mathrm{CO}_{2}$ atmosphere were grown to $80 \%$ confluence. The cells were electroporated with the RNA produced by in vitro transcription $\left(\mathrm{DI}_{1}: 532 \mathrm{ng}\right.$; $\mathrm{DI}_{0}: 476 \mathrm{ng}$; per 200,000 cells; equivalent to $1.7 \times 10^{6}$ and $5.6 \times 10^{6}$ RNA molecules per cell, respectively), in $100 \mu 1$ Nucleocuvette Vessels using the SF Cell solution and program DN-100 on a 4D Nucleofector X unit (Lonza). The efficiency of transfection was approximately $90 \%$ for both the $\mathrm{DI}_{1}$ and $\mathrm{DI}_{0}$

Peer) reviewing PDF | (2021:03:59206:1:0:NEW 25 May 2021) 
138 RNAs. Cells used for the control experiments were electroporated in the same way but without 139 RNA.

140

141

Virus culture. SARS-CoV-2 isolate USA-WA1/2020 was obtained from BEI resources (\#NR52281) and propagated in Vero-E6 cells. Virus stocks were prepared, and the titer as determined by plaque assays by serially diluting virus stock on Vero-E6 monolayers in the wells of a 24-well plate (Greiner bio-one, \#662160). The plates were incubated at room temperature in a laminar flow hood with hand rocking every ten minutes. After one hour, an overlay medium containing 1XMEM, 1\% Cellulose (Millipore Sigma, \#435244), 2\% FBS and 10mM Hepes 7.5, was added and the plates were incubated for a further 48 hours at $37^{\circ} \mathrm{C}$. The plaques were visualized by standard crystal violet staining. All work with SARS-CoV-2 was conducted in Biosafety Level-3 conditions at the Eva J Pell Laboratory of Advanced Biological Research, The Pennsylvania State University, following the guidelines approved by the Institutional Biosafety Committee (IBC\# 48724).

Coinfection and RNA extraction. 200,000 transfected cells were seeded in each well of a 24well plate (each well in triplicate; except the $24 \mathrm{~h}$ time-point of the initial coinfection, with 12 replicates) and incubated for 1 hour before being inoculated with SARS-CoV-2 at MOI=10. The medium containing the infectious SARS-CoV-2 viruses was removed after 1 hour and replaced with fresh medium. Cells were allowed to grow for 4, 8, 12 or 24 hours before RNA was extracted. The supernatant of cultures grown for 24 hours was used to infect new cells in 24 -well plates for one hour, then media was replaced with fresh media and RNA was extracted from the cells after another 24 hours. This step was repeated four times to obtain RNA from four consecutive passages. RNA was extracted using Quick RNA miniprep kit (Zymo, \#R1055) or TRIzol reagent (Invitrogen, \#15596026) followed by isopropanol precipitation.

RNA analysis. Equal amounts of total RNA were reverse transcribed into first-strand cDNA using Revert Aid First Strand cDNA Synthesis Kit (Fermentas). $2 \mu$ diluted cDNA (3pg-100ng depending on the experiment) mixed $2 \mu \mathrm{l}$ of $5 \mu \mathrm{M}$ primer mix (forward plus reverse), $1 \mu \mathrm{l}$ of 2 $\mu \mathrm{M}$ of probe and $5 \mu \mathrm{l}$ master mix $(2 \times)$ was used for qRT-PCR using TaqMan assay on a StepOnePlus instrument (Applied Biosystems) starting with polymerase activation at $95^{\circ} \mathrm{C}$ for 3 minutes, followed by 40 cycles of denaturation $\left(95^{\circ} \mathrm{C}, 15\right.$ seconds) and annealing/extension $\left(60^{\circ} \mathrm{C}, 1\right.$ minute). The amount of $\mathrm{WT}$ and synthetic $\mathrm{DI}_{1}$ or $\mathrm{DI}_{0}$ genomes were quantified (using StepOnePlus Software 2.3) by the comparative $C_{T}$ method [Livak and Schmittgen 2001]. All results were normalised with reference to the actin beta (ACTB) gene of Chlorocebus sabaeus; each sample was repeated three times and the average value was used; all absolute values reported are $2^{-\Delta \mathrm{CT}}$ values. Primers and probes for the $\mathrm{DI}_{1}$ and $\mathrm{DI}_{0}$ genomes were designed to amplify one of the junctions between portions of the WT genome; the probe for the $\mathrm{DI}_{1}$ genome was designed to span a junction that is not present in the WT genome [Figure 1] and is unlikely to be found in naturally occurring DIs. Our DI primer-probe sets gave consistently negative results in qPCR tests of virus only control plates. For the virus we used a modified version of the CCDC primer-probe set on ORF1. A BLAST search revealed no off-target sequences in the SARS-CoV-2 or in the Chlorocebus sabaeus genome. Primers and probes were labelled using the FAM dye, an IBFQ quencher and an additional internal (ZEN) quencher and were synthesised by Integrated DNA Technologies. The sequences are the following. 


$\begin{array}{lll}184 & \text { DI }_{1}: & \text { Forward: 5'-AGCTTGGCACTGATCCTTATG-3' } \\ 185 & & \text { Reverse: 5'-ACATCAACACCATCAACTTTTGTG-3' } \\ 186 & & \text { Probe: 5'-FAM/TTACCCGTGAACTCATGCGACAGG/IBFQ-3' } \\ 187 & & \\ 188 & \text { DI }_{0}: & \text { Forward: 5'-ATCAGAGGCACGTCAACATC -3' } \\ 189 & & \text { Reverse: 5'- TTCATTCTGCACAAGAGTAGACT -3' } \\ 190 & & \text { Probe: 5'-FAM/ AGCCCTATGTGTCGCTTTTCCGT /IBFQ-3' } \\ 191 & & \\ 192 & \text { SARS-CoV-2:Forward: 5'- CCCTGTGGGTTTTACACTTAA -3' } \\ 193 & & \text { Reverse: 5'- ACGATTGTGCATCAGCTGA -3' } \\ 194 & & \text { Probe: 5'-FAM/CCGTCTGCGGTATGTGGAAAGGTTATG /IBFQ-3' } \\ 195 & & \\ 196 & \text { ACTB: } & \text { Forward: 5'-AGGATTCATATGTGGGCGATG-3' } \\ 197 & & \text { Reverse: 5'-AGCTCATTGTAGAAGGTGTGG-3' } \\ 198 & & \text { Probe: 5'-FAM/AGCACGGCATCGTCACCAACT/IBFQ-3' }\end{array}$

199

200

201

202

203

204

We were able to quantify the relative amounts of DI and WT genomes by qRT-PCR, hence we report their relative values across time points or treatments; but since we use different primerprobe sets for the DI and WT genomes, we cannot compare the absolute values of the DI and WT genomes, hence we cannot measure the DI/WT ratio. For each genome $g$, however, if we define the $2^{-\Delta \mathrm{CT}}$ value at time point $i$ as $2^{-\Delta \mathrm{CT}}(g, i)$, we can measure the ratio of $2^{-\Delta \mathrm{CT}}(g, i)$ values at

205

206

207 two different time points $i=t_{1}, t_{2}$ as $R_{g}\left(t_{1}, t_{2}\right)=2^{-\Delta \mathrm{CT}}\left(g, t_{1}\right) / 2^{-\Delta C \mathrm{CT}}\left(g, t_{2}\right)$. The ratio $\rho\left(t_{1}, t_{2}\right)=$ $R_{\mathrm{DI}}\left(t_{1}, t_{2}\right) / R_{\mathrm{WT}}\left(t_{1}, t_{2}\right)$ reveals the rate of increase of the DI genome across time points $\left(t_{1}, t_{2}\right)$, relative to the increase of the WT genome across the same time points.

208

209

210

211

212

213

214

215

216

217

218

219

220

221

222

223

224

225

226

227

228

229

\section{Results}

Because of the fast degradation of the synthetic RNA inside cells (in the absence of the virus, 1 to $4 \%$ of the initial synthetic RNA can be detected by qRT-PCR 4 hours post transfection) and the lag between infection and viral protein production, it is not possible to quantify the replication rate of the $\mathrm{DI}_{1}$ and $\mathrm{DI}_{0}$ genomes, or even prove their replication, immediately after RNA transfection. It is possible, however, to quantify interference of the DI RNA with the WT virus in coinfections: within 24 hours of transfection, the $\mathrm{DI}_{1}$ genome reduced the amount of SARS-CoV-2 by approximately half compared to the amount of virus in control experiments (Welch's unequal variances t-test: $t_{15.3}=3.18, p=0.006$ ). The $\mathrm{DI}_{0}$ genome, instead, had no significant interference effect [Figure 2a] (Welch's unequal variances t-test: $t_{2.1}=-0.4, p=0.72$ ), which, in addition to serving as a control for the effect of DI particles, suggests that the parts of the $\mathrm{DI}_{1}$ genome missing in the $\mathrm{DI}_{0}$ genome are essential for replication.

24 hours post transfection the supernatants were collected and used to infect new cell monolayers. In these cells we detected (by qRT-PCR) the $\mathrm{DI}_{1}$ and WT genomes, from 4 to 24 hours after the transfer. The $\mathrm{DI}_{0}$ genome was not detected, suggesting that the parts of the $\mathrm{DI}_{1}$ genome missing in the $\mathrm{DI}_{0}$ genome have a positive effect on packaging. The transmission rate of the $\mathrm{DI}_{1}$ genome did not differ from that of the WT genome [Figure 2b] (Student's t-test: $t_{22}=0.49, p=0.62$ ), suggesting that the synthetic genome gets packaged into viral particles with essentially the same efficiency as the full-length virus, and that these viral particles are as 
230

231

232

233

234

235

236

237

238

239

240

241

242

243

244

245

246

247

248

249

250

251

252

253

254

255

256

257

258

259

260

261

262

263

264

265

266

267

268

269

270

271

272

273

274

275

infectious. In these cells coinfected by $\mathrm{DI}_{1}$ RNA and SARS-CoV-2, the WT genome again declined by approximately half in 24 hours [Figure 2c] (Student's t-test: $t_{4}=2.95, p=0.042$ ). The replication rate of the $\mathrm{DI}_{1}$ genome could now be quantified, revealing that it increases 3.3 times as fast as the WT virus [Figure 2c] (Student's t-test: $t_{4}=-2.74, p=0.052$ ).

Since the packaging efficiencies of the $\mathrm{DI}_{1}$ genome and of the WT genome are not significantly different, we can rule out the possibility that this observed relative increase in intracellular $\mathrm{DI}_{1}$ RNA is due to its lower rate of packaging. And since the supernatant from the previous passage was removed 1 hour after infection, the increase in $\mathrm{DI}_{1}$ RNA we observed is likely due to replication. Since the intracellular $\mathrm{DI}_{1}$ genomes in this second passage derive entirely from infectious viral particles produced in the first passage, we can conclude (in addition to our previous observation that the control $\mathrm{DI}_{0}$ RNA does not interfere with replication) that the reduction in the amount of WT observed in coinfections (here and in the first passage) is due to interference brought about by the faster replication of the $\mathrm{DI}_{1}$ genome, and not to any collateral effect of the initial transfection process.

We repeated the procedure by transferring the supernatant to new cells, coinfected with the WT virus, after 24 hours for four times. The $\mathrm{DI}_{1}$ genome was detected across all four passages and while we were unable to measure the absolute $\mathrm{WT} / \mathrm{DI}_{1} \mathrm{RNA}$ ratio (because the amount of $\mathrm{DI}_{1}$ RNA was below the level detectable by digital PCR), the $\rho\left(t_{1}, t_{2}\right)$ value increased approximately 3 times at every passage, consistent with the relative replication advantage and equal transmission efficiency we measured.. Our results, therefore, suggest that even a small amount of $\mathrm{DI}_{1} \mathrm{RNA}^{\mathrm{R}}$ (small enough to be below the detection limit of digital PCR, but high enough to be detectable by qRT-PCR) can interfere with the WT virus.

\section{Discussion}

DI particles have long been known to virologists [Gard et al. 1952, Huang \& Baltimore 1970] and their use in unravelling the location of functional elements of a genome is well known. Our synthetic DIs suggest that a disputed [Masters 2019] putative packaging sequence of SARSCoV-2 could indeed enable packaging of our synthetic defective genome - and therefore presumably acts as a packaging signal for the WT genome. However, because the difference between our $\mathrm{DI}_{1}$ and $\mathrm{DI}_{0}$ synthetic constructs is not limited to the portion with the putative packaging signal (part of nsp15), we cannot rule out that the packaging signals resides in the other parts of the $\mathrm{DI}_{1}$ genome that $\mathrm{DI}_{0}$ lacks, most notably a conserved region (28554-28569) with a SL5 motifs in the $\mathrm{N}$ partial sequence included in the $\mathrm{DI}_{1}$ genome but not in the $\mathrm{DI}_{0}$ genome. It is also possible that $\mathrm{DI}_{0}$ can be packaged but because it does not replicate efficiently, it is rapidly degraded after transfection and the amount of packaging does not meet the threshold for detection.

The interference with the WT virus is the most remarkable effect of our $\mathrm{DI}_{1}$ construct. As we have shown, while $\mathrm{DI}_{0}$ does not interfere significantly with $\mathrm{WT}, \mathrm{DI}_{1}$ induces a reduction of about $50 \%$ in the amount of WT virus in coinfections compared to infections with WT alone, and this is likely due to the faster replication of the $\mathrm{DI}_{1}$ genome. DI particles are often described as byproducts of inaccurate replication or as having a regulatory function for a viral quasi-species.

Peer] reviewing PDF | (2021:03:59206:1:0:NEW 25 May 2021) 
276 However, DIs can also be seen as defectors in the sense of evolutionary game theory [Szathmáry 277 1992, Turner \& Cao 1999, Brown 2001]: ultra-selfish replicators, able to freeride as parasites of 278 the full-length genome. As such, DI particles need not serve any purpose for the WT virus.

279

280

281

282

283

284

285

286

287

288

289

290

291

292

293

294

295

296

297

298

299

300

301

302

303

304

305

306

307

308

309

310

311

312

313

314

315

316

317

318

319

320

321

Indeed, DIs could be used as antivirals: by virtue of their faster replication in cells coinfected with the WT virus, DI genomes can interfere with the virus. Potentially, as the DI genomes increase in frequency among the virus particles pool, the process becomes more and more effective, until the decline in the amount of WT virus leads to the demise of both virus and DI. A similar therapeutic approach has been proposed for bacteria [Brown et al. 2009] and cancer [Archetti 2013]. The potential of DIs as antivirals has been suggested before [Marriott \& Dimmock 2010, Dimmock \& Easton 2014, Vignuzzi \& López 2019], and a synthetic DI particle could perhaps be immune to the evolution of resistance (although coevolution of viruses and DIs has been shown in Rhabdoviridae [Horodyski et al. 1983]). Unlike, for example, HIV and influenza, which are perhaps not ideal candidates because of their short genome, multiple genomic fragments and complex replication process, coronaviruses may be more amenable to DI therapy because of their long single fragment genome and relatively simple life cycles. While the immediate $50 \%$ reduction in virus load we observed is arguably not enough for therapeutic purposes, efficacy would compound over time (as the DIs increase in frequency) and a higher initial efficacy could be obtained using a delivery vector and an improved version of the DI genome.

\section{Conclusions}

We have established a proof of principle that a synthetic defective interfering SARS-CoV-2 can replicate in cells infected with the virus and interfere with its replication. Further experiments are needed to verify the potential of SARS-CoV-2 DIs as antivirals. Our experiments should be repeated in human lung cell lines, against other variants of SARS-CoV-2 and by transfecting DI RNA after infection, a more realistic simulation of therapy, which will, however, ultimately require in vivo experiments. An efficient delivery method should be devised to increase the initial amount of DI RNA and to deliver it in vivo. It would also be interesting to measure how the fraction of DI and WT genomes changes over time to test whether the DI genome drives the WT genome to extinction, or they coexist at a mixed equilibrium. Finally, it would be useful to analyse the long-term evolution of coinfections to test how SARS-CoV-2 and its DIs coevolve and whether resistant mutants can arise.

\section{References}

Archetti M. Evolutionarily stable anti-cancer therapies by autologous cell defection. Evolution, Medicine and Public Health 2013;1:161-172

Brian DA, Spaan WJM. Recombination and coronavirus defective interfering RNAs. Semin Virol. 1997;8(2):101-111

Brows SP. Collective action in an RNA virus. J. Evol. Biol. 2001;14:821-828.

Brown SP, West SA, Diggle SP, Griffin AS. Social evolution in micro-organisms and a Trojan horse approach to medical intervention strategies. Phil. Trans. R. Soc. B 2009;364:3157-3168

Peer) reviewing PDF | (2021:03:59206:1:0:NEW 25 May 2021) 
322

323

324

325

326

327

328

329

330

331

332

333

334

335

336

337

338

339

340

341

342

343

344

345

346

347

348

349

350

351

352

353

354

355

356

357

358

359

360

361

362

363

364

Brown CG, Nixon KS, Senanayake SD, Brian DA. An RNA stem-loop within the bovine coronavirus nsp1 coding region is a cis-acting element in defective interfering RNA replication. J Virol. 2007;81(14):7716-7724.

Chang RY, Hofmann MA, Sethna PB, Brian DA. A cis-acting function for the coronavirus leader in defective interfering RNA replication. J Virol. 1994;68(12):8223-8231.

Chang RY, Brian DA, cis Requirement for $\mathrm{N}$-specific protein sequence in bovine coronavirus defective interfering RNA replication. J Virol. 1996;70(4):2201-2207.

Cologna R, Hogue BG. Identification of a bovine coronavirus packaging signal. $J$ Virol. 2000; 74(1):580-583.

Cui L, Wang H, Ji Y, Yang J, Xu S, Huang X, Wang Z, Qin L, Tien P, Zhou X, Guo D, Chen Y. The Nucleocapsid Protein of Coronaviruses Acts as a Viral Suppressor of RNA Silencing in Mammalian Cells. J Virol. 2015;89(17):9029-9043.

Dalton K, Penzes Z, Wroe C, Stirrups K, Evans S, Shaw K, Brown TD, Britton P, Cavanagh D. Sequence elements involved in the rescue of IBV defective RNA CD-91. Adv Exp Med Biol. 1998;440:253-257.

DeGroot RJ, van der Most RG, Spaan WJ. The fitness of defective interfering murine coronavirus DI-a and its derivatives is decreased by nonsense and frameshift mutations. $J$ Virol. 1992;66(10):5898-5905.

Dimmock NJ, Easton AJ. Defective interfering influenza virus RNAs: time to reevaluate their clinical potential as broad-spectrum antivirals?. J Virol. 2014;88(10):5217-5227.

Escors D, Izeta A, Capiscol C, Enjuanes L. Transmissible gastroenteritis coronavirus packaging signal is located at the $5^{\prime}$ end of the virus genome. J Virol. 2003;77(14):7890-7902.

Fehr AR, Perlman S. Coronaviruses: an overview of their replication and pathogenesis. Methods Mol Biol. 2015;1282:1-23.

Fosmire JA, Hwang K, Makino S. Identification and characterization of a coronavirus packaging signal. J Virol. 1992;66(6):3522-3530.

Gard S, Von Magnus P, Svedmyr A, Birch-Andersen A. Studies on the sedimentation of influenza virus. Archiv für die Gesamte Virusforschung. 1952; 4:591-611.

Goebel SJ, Miller TB, Bennett CJ, Bernard KA, Masters PS. A hypervariable region within the 3' cis-acting element of the murine coronavirus genome is nonessential for RNA synthesis but affects pathogenesis. J Virol. 2007;81(3):1274-1287.

Graham RL, Sims AC, Baric RS, Denison MR. The nsp2 proteins of mouse hepatitis virus and SARS coronavirus are dispensable for viral replication. Adv Exp Med Biol. 2006;581:67-72.

Gribble J, Stevens LJ, Agostini ML, Anderson-Daniels J, Chappell JD, Lu X, et al. (2021) The coronavirus proofreading exoribonuclease mediates extensive viral recombination. PLoS Pathog 17(1): e1009226.

Horodyski FM, Nichol ST, Spindler KR, Holland JJ (1983) Properties of DI particle resistant mutants of vesicular stomatitis virus isolated from persistent infections and from undiluted passages. Cell 33(3):801-810

Hsieh PK, Chang SC, Huang CC, Lee TT, Hsiao CW, Kou YH, Chen IY, Chang CK, Huang TH, Chang MF. Assembly of severe acute respiratory syndrome coronavirus RNA packaging signal into virus-like particles is nucleocapsid dependent. J Virol. 2005 Nov;79(22):1384813855 .

Peer] reviewing PDF | (2021:03:59206:1:0:NEW 25 May 2021) 
365

366

367

368

369

370

371

372

373

374

375

376

377

378

379

380

381

382

383

384

385

386

387

388

389

390

391

392

393

394

395

396

397

398

399

400

401

402

403

404

405

406

407

408

409
Hsin WC, Chang CH, Chang CY, Peng WH, Chien CL, Chang MF, Chang SC. Nucleocapsid protein-dependent assembly of the RNA packaging signal of Middle East respiratory syndrome coronavirus. J Biomed Sci. 2018;25(1):47.

Huang AS, Baltimore D. Defective viral particles and viral disease processes. Nature 1970;226: 325-327.

Izeta A, Smerdou C, Alonso S, et al. Replication and packaging of transmissible gastroenteritis coronavirus-derived synthetic minigenomes. J Virol. 1999;73(2):1535-1545.

Joo M, Makino S. The effect of two closely inserted transcription consensus sequences on coronavirus transcription. J Virol. 1995;69(1):272-280.

Kim YN, Jeong YS, Makino S. Analysis of cis-acting sequences essential for coronavirus defective interfering RNA replication. Virology. 1993b;197(1):53-63.

Kim YN, Lai MM, Makino S. Generation and selection of coronavirus defective interfering RNA with large open reading frame by RNA recombination and possible editing. Virology. 1993b;194(1):244-253.

Kim YN, Makino S. Characterization of a murine coronavirus defective interfering RNA internal cis-acting replication signal. J Virol. 1995;69(8):4963-4971.

Kim D, Lee JY, Yang JS, Kim JW, Kim VN, Chang H. The Architecture of SARS-CoV-2 Transcriptome. Cell. 2020;181(4):914-921.e10.

Kuo L, Masters PS. Functional analysis of the murine coronavirus genomic RNA packaging signal. J Virol. 2013;87(9):5182-5192.

Livak KJ, Schmittgen TD. Analysis of relative gene expression data using real-time quantitative PCR and the 2(-Delta Delta C(T)) Method. Methods. 2001;25(4):402-408.

Lorenz R, Bernhart SH, Höner zu Siederdissen C, Tafer H, Flamm C, Stadler PF, Hofacker IL. ViennaRNA Package 2.0. Algorithms for Molecular Biology 2011;6:1-26.

Makino S, Fujioka N, Fujiwara K. Structure of the intracellular defective viral RNAs of defective interfering particles of mouse hepatitis virus. J Virol. 1985;54(2):329-336.

Makino S, Shieh CK, Soe LH, Baker SC, Lai MM. Primary structure and translation of a defective interfering RNA of murine coronavirus. Virology. 1988;166(2):550-560.

Makino S, Yokomori K, Lai MM. Analysis of efficiently packaged defective interfering RNAs of murine coronavirus: localization of a possible RNA-packaging signal. $J$ Virol. 1990;64(12):6045-6053.

Marriott AC, Dimmock NJ. Defective interfering viruses and their potential as antiviral agents. Rev Med Virol. 2010;20:51-62.

Masters PS. Coronavirus genomic RNA packaging. Virology. 2019;537:198-207.

Méndez A, Smerdou C, Izeta A, Gebauer F, Enjuanes L. Molecular characterization of transmissible gastroenteritis coronavirus defective interfering genomes: packaging and heterogeneity. Virology. 1996;217(2):495-507.

Martin CT, Coleman JE. Kinetic analysis of T7 RNA polymerase-promoter interactions with small synthetic promoters. Biochemistry 1987;26:2690-2696

Milligan JF, Groebe DR, Witherell GW, Uhlenbeck OC. Oligoribonucleotide synthesis using T7 RNA polymerase and synthetic DNA templates. Nucleic Acids Res. 1987;15(21):8783-8798.

Morales L, Mateos-Gomez PA, Capiscol C, del Palacio L, Enjuanes L, Sola I. Transmissible gastroenteritis coronavirus genome packaging signal is located at the $5^{\prime}$ end of the genome and promotes viral RNA incorporation into virions in a replication-independent process. $J$ Virol. 2013;87(21):11579-11590. 
410 Penzes Z, Tibbles K, Shaw K, Britton P, Brown TD, Cavanagh D. Characterization of a

411 replicating and packaged defective RNA of avian coronavirus infectious bronchitis virus.

412 Virology. 1994;203(2):286-293.

413 Raman S, Bouma P, Williams GD, Brian DA. Stem-loop III in the 5' untranslated region is a cis-

414 acting element in bovine coronavirus defective interfering RNA replication. $J$ Virol.

415 2003;77(12):6720-6730.

416 Rangan R, Zheludev IN, Hagey RJ, Pham EA, Wayment-Steele HK, Glenn JS, Das R. RNA

417 genome conservation and secondary structure in SARS-CoV-2 and SARS-related viruses: a

418 first look. RNA. 2020;26(8):937-959.

419 Szathmáry E. Natural selection and dynamical coexistence of defective and complementing virus

420 segments. J Theor Biol. 1994;157(3):383-406.

421 Thiel V, Siddell SG, Herold J. Replication and transcription of HCV 229E replicons. p6. Adv

$422 \quad$ Exp Med Biol. 1998;440:109-113.

423 Turner PE, Chao L. Prisoners' dilemma in an RNA virus. Nature 1999;398: 441-443.

424

425

426

427

428

429

430

431

432

433

434

435

436

437

438

439

440

441

442

443

444

445

446

van der Most RG, Bredenbeek PJ, Spaan WJ. A domain at the 3' end of the polymerase gene is essential for encapsidation of coronavirus defective interfering RNAs. J Virol. 1991;65(6):3219-3226.

van der Most RG, Luytjes W, Rutjes S, Spaan WJ. Translation but not the encoded sequence is essential for the efficient propagation of the defective interfering RNAs of the coronavirus mouse hepatitis virus. J Virol. 1995;69(6):3744-3751.

van Marle G, Luytjes W, van der Most RG, van der Straaten T, Spaan WJ. Regulation of coronavirus mRNA transcription. J Virol. 1995;69(12):7851-7856.

Vignuzzi M, López CB. Defective viral genomes are key drivers of the virus-host interaction. Nat Microbiol. 2019;4(7):1075-1087.

Williams GD, Chang RY, Brian DA. A phylogenetically conserved hairpin-type 3' untranslated region pseudoknot functions in coronavirus RNA replication. J Virol. 1999;73(10):83498355.

Woo J, Lee EY, Lee M, Kim T, Cho YE. An in vivo cell-based assay for investigating the specific interaction between the SARS-CoV N-protein and its viral RNA packaging sequence. Biochem Biophys Res Commun. 2019;520(3):499-506.

Wu F, Zhao S, Yu B, Chen YM, Wang W, Song ZG, ... Zhang YZ. A new coronavirus associated with human respiratory disease in China. Nature 2020;579:265-269.

Yang D, Leibowitz JL. The structure and functions of coronavirus genomic $3^{\prime}$ and 5 ' ends. Virus Res. 2015;206:120-133.

Zou L, Ruan F, Huang M, Liang L, Huang H, Hong Z, ... Wu J. SARS-CoV-2 viral load in upper respiratory specimens of infected patients. The New England Journal of Medicine 2020;

447 
448 Figure 1. Synthetic defective interfering viruses. a: Three portions of the wild type (WT) 449 SARS-CoV-2 genome were used to create a synthetic defective interfering genome (DI $\left.{ }_{1}\right)$ and a 450 shorter version $\left(\mathrm{DI}_{0}\right)$ comprising only parts of the two terminal portions. Numbers delimiting the 451 portions refer to positions in the SARS-CoV-2 genome. The first position is mutated $(A \rightarrow C)$ in 452 both $\mathrm{DI}_{1}$ and $\mathrm{DI}_{0}$. Open rectangles show the position of the probes and primers used. $\mathbf{b}$ : To 453 produce synthetic DI particles, DNA constructs corresponding to the RNA sequence of $\mathrm{DI}_{1}$ or $454 \mathrm{DI}_{0}$ were transcribed into RNA in vitro using T7 RNA polymerase and transfected into Vero-E6 455 cells that were then infected with SARS-CoV-2. The supernatant from these cell cultures was 456 used to infect new cells.

457

458

459

460

461

462

463

464

465

466

467

468

469

470

471
Figure 2. DI reduces the amount of SARS-CoV-2 by half; it replicates 3 times faster; and it is transmitted with the same efficiency. a: Growth rates (absolute amount relative to the amount at 4 hours) of WT in controls (gray) and in coinfections with $\mathrm{DI}_{1}$ (blue) or $\mathrm{DI}_{0}$ (green); growth relative to controls at the same time point; and detail at 24 hours. b: Transmission efficiency of WT (blue) and DI $_{1}$ (yellow) in coinfections: the amount, measured by qRT-PCR, immediately before passaging divided by the average amount measured almost immediately (4 hours) after passaging (using the supernatant to infect new cells 24 hours after initial infection). $\mathrm{DI}_{0}$ was detected inside the cells but not in the supernatant. c: Growth rates (absolute amount relative to the amount at 4 hours) of WT in controls (gray) and in coinfections (blue); growth relative to controls at the same time point; and detail at 24 hours. Growth rates (absolute amount relative to the amount at 4 hours) of WT (blue) and $\mathrm{DI}_{1}$ (yellow) in coinfections; growth relative to that of WT in coinfections at the same time point; and detail at 24 hours. 


\section{Figure 1}

Synthetic defective interfering viruses.

a: Three portions of the wild type (WT) SARS-CoV-2 genome were used to create a synthetic defective interfering genome $\left(\mathrm{DI}_{1}\right)$ and a shorter version $\left(\mathrm{DI}_{0}\right)$ comprising only parts of the two terminal portions. Numbers delimiting the portions refer to positions in the SARS-CoV-2 genome. The first position is mutated $(A \rightarrow C)$ in both $\mathrm{DI}_{1}$ and $\mathrm{DI}_{0}$. Open rectangles show the position of the probes and primers used. $\mathbf{b}$ : To produce synthetic DI particles, DNA constructs corresponding to the RNA sequence of $\mathrm{Dl}_{1}$ or $\mathrm{DI}_{0}$ were transcribed into RNA in vitro using $T 7$ RNA polymerase and transfected into Vero-E6 cells that were then infected with SARS-CoV-2. The supernatant from these cell cultures was used to infect new cells. 
a

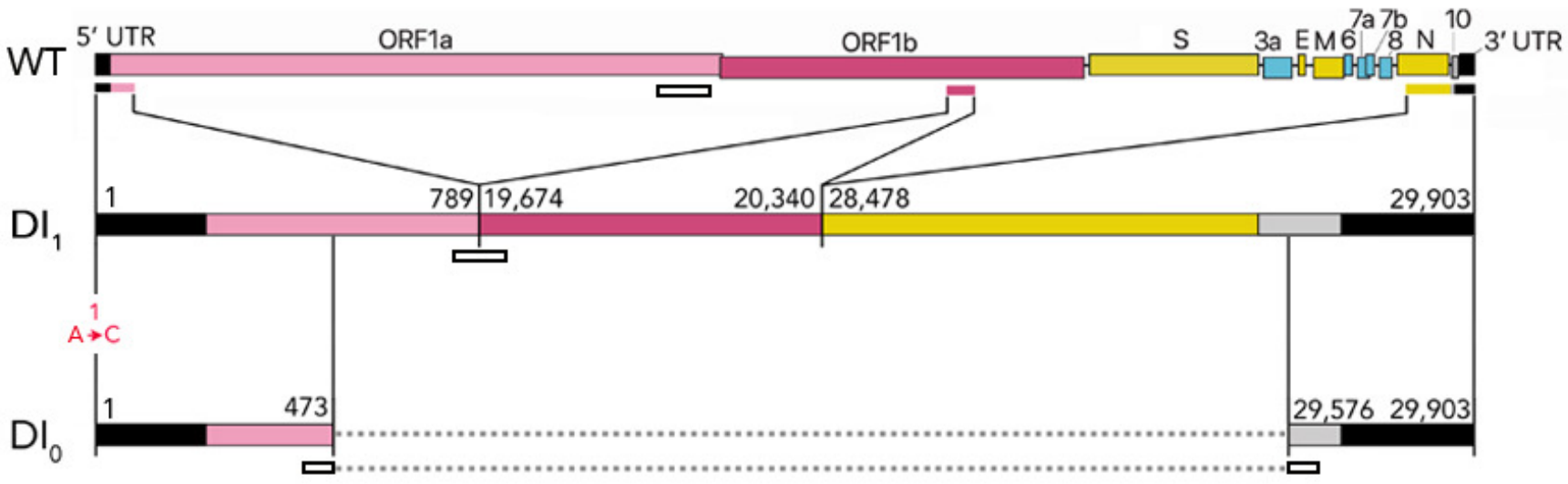

b

cloning $\rightarrow$ in vitro transcription $\rightarrow$ transfection $\rightarrow$ passage SARS-CoV-2

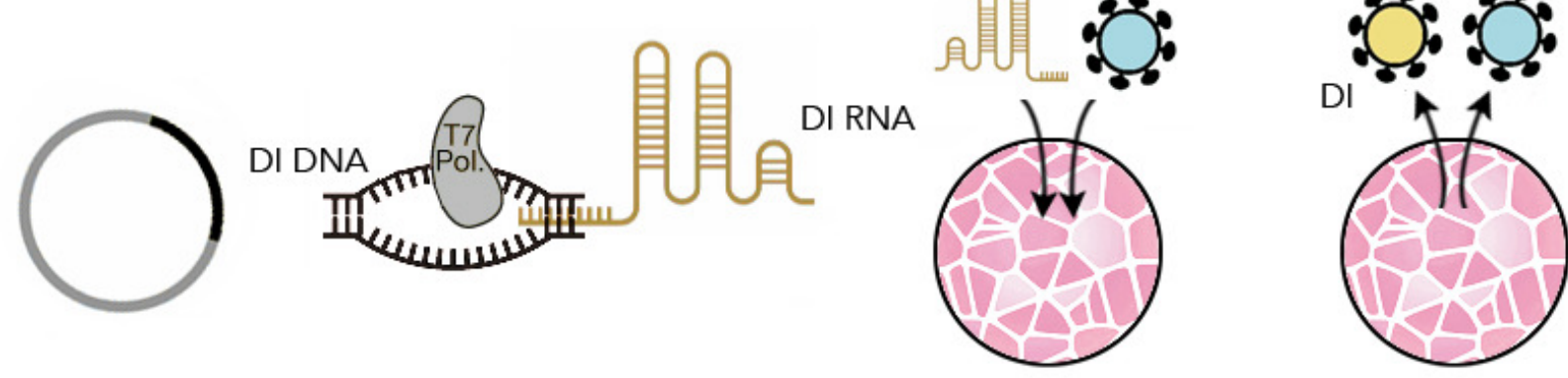




\section{Figure 2}

$\mathrm{DI}_{1}$ reduces the amount of SARS-CoV-2 by half; it replicates 3 times faster; and it is transmitted with the same efficiency

a: Growth rates (absolute amount relative to the amount at 4 hours) of WT in controls (gray) and in coinfections with $\mathrm{DI}_{1}$ (blue) or $\mathrm{DI}_{0}$ (green); growth relative to controls at the same time point; and detail at 24 hours. b: Transmission efficiency of WT (blue) and $\mathrm{DI}_{1}$ (yellow) in coinfections: the amount, measured by qRT-PCR, immediately before passaging divided by the average amount measured almost immediately (4 hours) after passaging (using the supernatant to infect new cells 24 hours after initial infection). $\mathrm{DI}_{0}$ was detected inside the cells but not in the supernatant. c: Growth rates (absolute amount relative to the amount at 4 hours) of WT in controls (gray) and in coinfections (blue); growth relative to controls at the same time point; and detail at 24 hours. Growth rates (absolute amount relative to the amount at 4 hours) of WT (blue) and $\mathrm{DI}_{1}$ (yellow) in coinfections; growth relative to that of WT in coinfections at the same time point; and detail at 24 hours. 


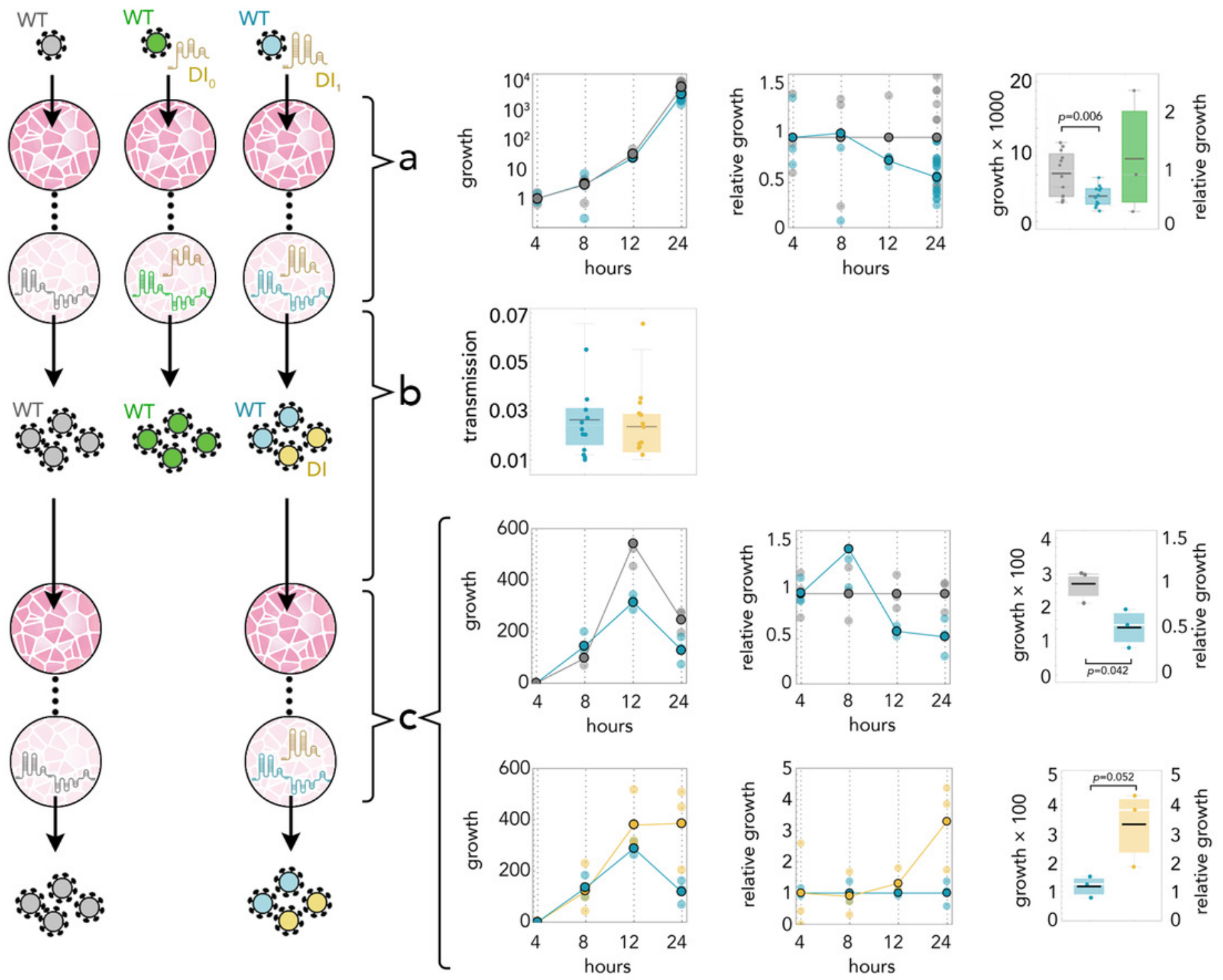

